\title{
PENGARUH KEPEMIMPINAN DAN BUDAYA ORGANISASI TERHADAP KINERJA GURU PADA SMP-SMA KOSGORO KOTA TANGERANG
}

\author{
Muhammad Gandung, Windy Gustia Wardani \\ Staf Pengajar Fakultas Ekonomi Universitas Pamulang \\ 1) dosen universitas pamulang,email : dosen02020@unpam.ac.id \\ ${ }^{2)}$ dosen universitas pamulang, email : dosen01579@unpam.ac.id
}

\begin{abstract}
ABSTRAK
Peneliti menggunakan metode deskripsi kuantitatif. Populasi dan sampel yang diteliti sebanyak 40 guru. Mengetahui pengaruh kepemimpinan dan budayaorganisasi terhadap kinerja guru. Maka pengujian tersebut adalah signifikan atau valid. Berdasarkan hasil penelitian, maka terdapat temuan sebagai berikut kepemimpinan dan budaya organisasi secara parsial maupun secara simultan terbukti berpengaruh positif dan signifikan terhadap kinerja guru. Kepemimpinan dan budaya organisasi secara Bersama-sama memberikan kontribusi sebesar 71.1\% terhadap kinerja guru dan sisanya $28.9 \%$ di sebab kan karna faktor lain..
\end{abstract}

\section{Kata Kunci: Kepemimpinan, Budaya Organisasi dan Kinerja}

\section{ABSTRACT}

Researchers use quantitative description methods. The population and sample studied were 40 teachers. Knowing the influence of leadership and organizational culture on teacher performance. From the test results are significant or valid. Based on the research results, there are the following findings that leadership and organizational culture partially or simultaneously are proven to have a positive and significant effect on teacher performance. Leadership and organizational culture collectively contribute $71.1 \%$ to teacher performance and the remaining $28.9 \%$ is due to other factors.

Keywords: leadership, organizational culture and teacher performance 


\section{PENDAHULUAN}

\section{A. Latar Belakang}

belajar bisa di lakukan di sekolah dan merupakan tempat terjadinya proses belajar mengajar mempunyai tugas pokok guna membikin cerdas anak.

Meninggikan kualitas hal yang berat, walaupun pemerintah berusaha melalui pembaharuan kurikulum, peningkatan profesionalisme tenaga kependidikan tenaga staf lainnya. hal ini tidak dapat tercukupi meskipun sudah semua usaha dilaksanakan dengan semaksimal mungkin. Sehingga sekolah yang merupakan suatu lembaga pendidikan formal dapat menunjukan tingkat kemampuan kepemimpinan dalam rangka pelaksanaan belajar mengajar yang ditunjukan oleh hasil belajar yang sangat bermutu bagi peserta didik.Perihal ini nampak dari gejala-gejala sbb, yaitu: (1) adanya pegawai yang tidak serius. Hal ini terlihat pada saat bel sudah berbunyi, Pegawai masih duduk di ruang majelis Pegawai untuk bercerita. Pada saat jam mengajar sebagian Pegawai terlihat duduk di ruang majelis Pegawai sambil mengobrol dengan sesama Pegawai sementara siswa di dalam kelas disuruh mengerjakan latihan. (2) adanya pegawai yang lalai pada SOP. Contohnya Pegawai tidak mengisi buku batas sesuai dengan jumlah hari pelaksanaan pembelajaran. (3) adanya pegawai yang telat melakukan tugas. Contohnya, RPP yang seharusnya dibuat sebelum melaksanakan pembelajaran hanya dikerjakan apabila ada sidak pengawas atau kepala sekolah.

Hasil pengamatan yang berdasarkan permasalahan di atas maka penulis merumuskan permasalahan tersebut melalui tesis yang berjudul: "Pengaruh Kepemimpinan Dan Budaya Organisasi Terhadap Kinerja Guru pada SMPSMA Kosgoro Kota Tangerang"

\section{B. Perumusan Masalah}

Berdasarkan baatasan maasalah di ialah :

1. AdanyaKepemimpinan Terhadaap Kinerja Guuru?

2. AdanyaBudaya Organisasi TerhadapKinerja Guru?

3. Adanya Pengaruh Signifikan Kepemimpinan Kepala Sekolah Dan Budaya Organisasi Terhadap Kinerja Guru?

\section{Tujuan Penelitian}

Bermaksut untuk :

1. pengaruh Kepemimpinan terhadap kinerja.

2. pengaruh Budaya Organisasi terhadap kinerja. 
3. pengaruh kepemimpinan kepala sekolah dan budaya organisasi terhadap kinerja.

\section{LANDASAN TEORI}

\section{A. MSDM}

Pendapat Moses N. Kiggundu dalam buku Ambar dan Rosidah (2009) adalah mencapai sesuatu visi dengan memanfaatkan karyawan dengan mengajak serta membina dalam sasaran yang berkitan dengan perkumpulan yang efektif.

\section{B. Kepemimpinan}

Kepemimpinan adalah upaya dalam usaha mempengaruhi dengan seni mengajak seseorang untuk menuju sasaran yang sudah di tetapkan

\section{Budaya Organisasi}

Cara untuk merasakan, berpikir, bertindak untuk memperoleh suatu karakteristik dan sebuah keyakinan, sikap dan nilai, norma, dan asumsi yang tidak dapat diungkapkan dan dapat membentuk cara orang berperilaku dan melakukan sesuatu dalam menjalankan pekerjaan dengan menganut atau mengikuti tata nilai yang mengacu kepada apa yang diyakini merupakan suatu sistem pengertian bersama. budaya organisasi dipengaruhi oleh;
a. Sedangkan indikator-indikator
b. kebiasaan mengikuti norma organisasi
c. kebiasaan menjalankan tanggung jawab
d. kebiasaan mempunyai keyakinan diri
e. menerapkan nilai-nilai kejujuran
f. kebiasaan menerapkan sikap kerjasama
g. kebiasaan menerapkan integritas diri
h. kemampuan beradaptasi

Dalam indikator-indikator tersebut menunjukkan bahwa dalam budaya organisasi berkewajiban melakukan dan melaksanakan yang diyakini bersama. Selanjutnya dari indikator-indikator dari budaya organisasi menjadi inspirasi dalam penyusunan kisi-kisi dalam membuat instrumen/koesioner penelitian. Indikator

\section{Budaya Organisasi}
a. Kerjasama
b. Kesadaran
c. Perilaku Kerja
d. Toleransi Kerja
e. Kreativitas dan Inovasi 


\section{Kinerja}

kinerja sebagai suatu karyawan membutuhkan perusahaan guna membuat produk dan layanan berkualitas, karyawan merupakan ujung tombak perusahaan, kinerjanya perlu ditinjau agar semakin maksimal.

\section{E. Hipotesis Penelitian}

Hasil hipotesis sebagai berikut:

a. Hipotesis nol (Ho) : $\mathbf{r}=\mathbf{0}$

Tidak ada dampak X1 Dan X2 Terhadap Y

b. Hipotesis (Ha) : $\mathbf{r} \neq \mathbf{0}$

Adanya dampak Signifikan X1 Dan X2 Terhadap Y

\section{METODE PENELITIAN}

penulis melakukan penelitian pada Pendidikan SMP-SMA Kosgoro Kota Tangerang.

Dijalankan pada Januari 2020 sampai April 2020. Dalam melakukan studi pendahuluan penulis mengidentifikasi beberapa masalah yang terjadi di lapangan).

Sampel yang digunakan adalah seluruh kinerja guru SMP-SMA Kosgoro Kota Tangerang yang berjumlah 40 guru.
IV. PEMBahaSAN HaSIL

1. Pengaruh Secara Parsial

a. Variable X1 terhadap $Y$

Hasil R Square 0,672 dalam persen persen yaitu $67 \%$. Artinya persentase mempunyai daya tarik yang sebesar $33 \%$ sedangkan sisanya $83 \%$ ada sebab lain. Karnanya hal itu memiliki dampak yang signifikan.

\section{b. Variable X2 terhadap Y \\ Perolehan R Square 0,526 dan di ubah} menjadi persen yaitu 52\%. Artinya persentase $52 \%$ sedangkan sisanya $48 \%$ ada sebab lain. Karnanya hal itu memiliki dampak yang signifikan.

Dalam teori nya secara tidak langsung menunjukkan bahwa setiap individu atau seseorang yang berada di dalam lingkungan kelompok/organisasi harus melakukan suatu kebiasaan untuk menjalankan aturanaturan, norma-norma yang terkait dengan adat-istiadat atau sesuatu yang sudah dijalankan oleh masyarakat setempat secara turun menurun. Sehingga seluruh perilaku masyarakat tersebut dalam menjalankan aktivitasnya sebagai budaya aktivitas yang sudah melekat dan dalam jiwa setiap orang di lingkungan organisasi tersebut. 
Jurnal Semarak,Vol.3,No.3,OKTOBER 2020, Hal (146-152)

@Prodi Manajemen Fakultas Ekonomi Universitas Pamulang

2. Pengaruh Secara Simultan Pengaruh Kepemimpinan dan Budaya Organisasi Terhadap Kinerja Guru

Hasil nilai R Square sebesar 0,711 dan diubah menjadi persen yaitu $71,1 \%$. sedangkan sisanya $29 \%$ ada sebab lain.

Karnanya hal itu memiliki dampak yang signifikan berpengaruh sebesar $71.1 \%$. Sedangkan sisanya di pengaruhi variabel lainnya selain kepemimpinan dan budaya organisasi.

\section{KESIMPULAN DAN SARAN}

\section{A. Kesimpulan}

Disimpulkan hal-hal sebagai berikut:

1. Perolehan nilai R Square sebesar 0,672 dalam persen yaitu $67 \%$. Artinya bahwa persentase sebesar $67 \%$ sedangkan sisanya $33 \%$ di sebabkan hal lain.

2. Perolehan nilai R Square sebesar 0,526 dan di ubah menjadi persen yaitu 52\%. Artinya bahwa persentase sebesar $52 \%$ sedangkan sisanya $48 \%$ di sebabkan hal lain.

3. Perolehan nilai R Square sebesar 0,711 dan diubah menjadi persen yaitu $71.1 \%$. Artinya bahwa presentase sebesar 71,1\%, sedangkan sisanya $29 \%$ di sebabkan hal lain.

\section{B. Saran}

Dapat di jabarkan dalam upaya meningkatkan Kinerja Guru Pada SMPSMA Kosgoro Kota Tangerang. Memberikan masukan:

1. Komunikasi yang perlu disambung erat antara pemimpin dan bawahannya dengan baikdan menciptakan keharmonisasian dengan baik.

2. Menciptakan kebiasaan atau Budaya yang baik di lingkugan sekolah guna dapat meningkatkan semangat dalam mengajar serta selalu tidak menimbulkan perkelompokan dalam pergaulan di lingkungan sekolah

\section{DAFTAR PUSTAKA}

Abdullah, T, 2012, Manajemen Arikunto. 2013. Prosedur Penelitian Suatu Pendekatan Praktek. Jakarta: PT Abas, Erjati. 2017. Magnet Kepemimpinan Kepala Madrasah Terhadap Kinerja Guru. Jakarta: PT Alex Media Komputindo.

Danim, Sudarwan. 2010. Pengantar Kependidikan. Bandung : Alfabeta

Dwiwibawa, Rudi. 2008. Siap jadi Pemimpin? Latihan Dasar Kepemimpinan. Jogyakarta: Kanisius media. 
Fahmi, Irham 2012 Manajemen

Kepemimpinan Teori \& Aplikasi.

Bandung: PT Alfabeta.

Fatta, Hussein 2017.Kepuasan Kerja dan Kinerja Pegawai Yogyakarta:

Elmatera.

Krisnaldy, K., Pasaribu, V. L. D., \& Senen, S. (2019). Pengaruh Budaya Organisasi, Lingkungan Kerja Dan Iklim Organisasi Terhadap Motivasi Pegawai Serta Dampaknya Terhadap Kepuasan Kerja. Jurnal Semarak, 2(2), 164-183.

Kristanti, Desi, Ria Lestari Pangastuti. 2019. Kiat- kiat merangsang Kinerja Karyawan bagi Produksi. Surabaya: Media Sahabat Cendekia.

Mulyasa. 2009. Menjadi Kepala Sekolah Profesional. Bandung: Rosada

Mulyasa, E. 2010 Menjadi Kepala Sekolah Profesional, Bandung : PT Remaja Rosdakarya.

Nurviza, Cut., dkk.2019. Pengaruh budaya organisasi dan kepemimpinan kepala sekolah terhadap kinerja guru pada SMA Unggul Negeri 2 Boarding School Kota Banda Aceh. Jurnal Magister Administrasi Pendidikan Pascasarjana Universitas Syiah Kuala Volume 7, No.1, Februari 2019, pages 41-46 ISSN 2302-0156

Pasaribu, V. L. D., Krisnaldy, K., \& Warasto, H. N. (2020). Pengaruh Gaya Kepemimpinan, Disiplin Kerja Dan Kompensasi Terhadap Kinerja Pegawai (Studi kasus kelurahan
Pisangan Ciputat). Jurnal Disrupsi Bisnis: Jurnal Ilmiah Prodi Manajemen, Fakultas Ekonomi, Universitas Pamulang, 3(1).

Pasaribu, V. L. D., \& Krisnaldy, K. (2020, June). PENGARUH GAYA KEPEMIMPINAN, DISIPLIN KERJA DAN KOMPENSASI TERHADAP HASIL KINERJA KARYAWAN KELURAHAN PISANGAN CIPUTAT. In PROCEEDINGS (Vol. 1, No. 1).

Purnaya, I Gusti Ketut. 2016. Manajemen Sumber Daya Manusia. Yogyakarta: Andi.

Purwanto, Ngalim, 2009. Aministrasi dan Supervisi Pendidikan. Bandung: PT. Remaja Rosdakarya.

Rai, I Gusti Agung. 2008. Audit Kinerja Kepada Sektor Publik Konsep, Praktik, dan Studi Kasus. Jakarta: Salemba Empat.

Riniwati, Harsuko. 2016. Manajemen Sumberdaya Manusia (Aktivitas Utama dan Pengembangan SDM). Malang: UB Pres.

Rismawati dan Mattalata. 2018. Evaluasi Kinerja Penilaian Kinerja Atas Dasar Prestasi Kerja Berorientasi Kedepan. Celebes Media Perkasa.

Sari, Rahmila., dkk. 2012. Pengaruh kepemimpinan, motivasi, dan stress kerja terhadap kinerja karyawan pada Bank Syariah Mandiri Kantor Cabang Makassar. Jurnal Analisis, Volume 1, No.1. pages 87-93, ISSN 2302-1001. 
Santris, Billy. 2019. Pengaruh kepemimpinan dan komitmen organisasi terhadap kinerja guru dengan motivasi sebagai variabel intervening pada SMA Sutomo 1 Medan. Journal of Accounting \& Management Innovation Volume 3, No. 2, July 2019, pages 91-116 ISSN 25485709.

Sarvedi, Reza.,dkk. 2016. Pengaruh kepemimpinan, budaya organisasi dan kompetensi terhadap kinerja pegawai serta implikasinya pada kinerja sekretariat Kabupaten Pidie Jaya. Jurnal Perspektif Ekonomi Darussalam Volume 2, No.2, September 2016, pages 201-217, ISSN. 2502-6976.

Sulaksono, Hari. 2019. Budaya Organisasi dan Kinerja. Yogyakarta: CV Budi Utama.

Sutrisno, Edy. 2010. Budaya Organisasi. Jakarta: Prenadamedia Group.

Wardani, Windy Gustia. 2017. Pengaruh Kepemimpinan, Motivasi dan Disiplin Kerja Terhadap Kinerja Karyawan (Pada Perusahaan Travel Umroh dan Haji Kota Tangerang). EDUKA Jurnal Pendidikan, Hukum dan Bisnis Universitas Pamulang, 2(4), 51-62. 